\title{
Diagnosis and management of irritable bowel syndrome in adults in primary care: summary of NICE guidance
}

Clarification-This NICE guideline summary (BMJ 2008;336:556, doi:10.1136/bmj.39484.712616.AD) has now been superseded by a summary of updated guidance at www. bmj.com/content/350/bmj.h701.
Cite this as: BMJ 2015;350:h1216

๑ BMJ Publishing Group Ltd 2015 